\title{
Pequena produção mercantil, meio técnico e rede colonial: o processo de formação territorial do Vale do Rio Pardo-RS*
}

Rogério Leandro Lima da Silveira**

\section{Resumo}

Esse artigo aborda o processo inicial de formação do território da região do Vale do Rio Pardo, no Rio Grande do Sul, notadamente o desenvolvimento da pequena produção mercantil advindo do povoamento das áreas de mata através da instalação a partir de 1849 de núcleos coloniais de imigrantes alemães organizados em pequenas propriedades agrícolas. Nesse processo analisamos a importância da cultura do fumo na pequena produção mercantil das colônias e a relação de subordinação das famílias camponesas de fumicultores aos comerciantes instalados nas povoações coloniais e em Porto Alegre. Abordamos a introdução de inovações técnicas nas esferas da produção e da circulação dos produtos coloniais, bem como analisamos a constituição e o funcionamento da rede de comercialização de produtos coloniais, sua materialização no território regional e seus reflexos na progressiva especialização da economia regional pela fumicultura, e nos novos usos do território e na dinâmica de organização espacial da região.

Palavras-chave: Pequena produção mercantil; Fumicultura; Meio técnico; Rede comercial colonial; Região.

* Este artigo é uma versão resumida do capítulo 4 de nossa tese de doutorado: Complexo agroindustrial do fumo e território: a formação do espaço urbano e regional no Vale do Rio Pardo-RS, defendida junto ao Programa de Pós-Graduação em Geografia da UFSC, em 2007.

** Doutor em Geografia pela UFSC. Professor do Programa de PósGraduação em Desenvolvimento Regional e do Departamento de História e Geografia da UNISC (rlls@unisc.br).

Geosul, Florianópolis, v. 25, n. 50, p 59-81, jul./dez. 2010 
SILVEIRA, R.L.L. da. Pequena produção mercantil, meio técnico e rede ...

Small mercantile production, technical environment, and colonial net: the process of territoryal formation of Rio Pardo Valley-RS

\begin{abstract}
The present article approaches the initial process of the territory formation of Rio Pardo Valley area, in Rio Grande do Sul, especially the development of the small mercantile production originated from the settlement of the forest areas through the installation since 1849 of German immigrants' colonial nuclei organized in small agricultural properties. In that process we have analyzed the importance of the tobacco culture in the small mercantile production of the colonies and the subordination relationship of the tobacco growers families with the merchants installed in the colonial populations and in Porto Alegre. We have approached the introduction of technical innovations in the production and circulation spheres of the colonial products. In addition, we analyzed the constitution and the operation of the commercialization net of colonial products, their materialization in the regional territory and their reflexes in the progressive specialization of the regional economy by the tobacco culture, and in the new uses of the territory and in the dynamics of the region's spatial organization.
\end{abstract}

Key words: Small mercantile production; Tobacco culture; Technical environment; Colonial commercial net; Region.

\title{
Introdução
}

Neste artigo abordamos o momento inicial da formação do território da região do Vale do Rio Pardo, localizado na parte centro-oriental do Rio Grande do Sul. (Figura 1). Trata-se do processo de ocupação e de povoamento das áreas de mata localizadas na área setentrional da região através da criação de núcleos coloniais estatais e privados, a partir de 1849, destinados 
SILVEIRA, R.L.L. da. Pequena produção mercantil, meio técnico e rede ... às famílias de imigrantes alemães e italianos, assentadas em pequenas propriedades rurais, com o objetivo de produzir alimentos e matérias-primas para o mercado interno nacional.

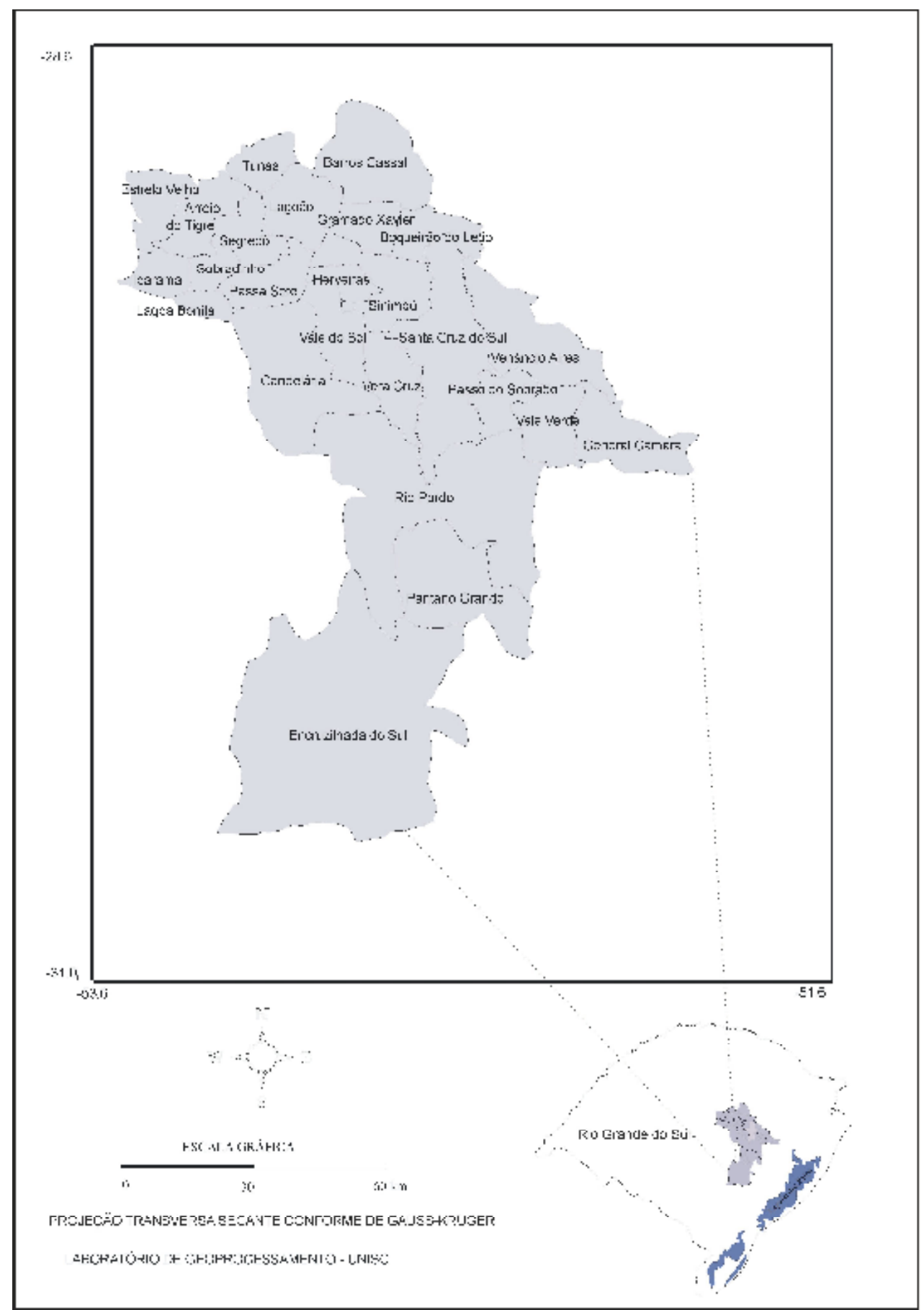

FIGLRA I YALE DORIO J'MLDO- IRS

Geosul, v.25, n.50, 2010 
SILVEIRA, R.L.L. da. Pequena produção mercantil, meio técnico e rede ...

Esse período também se caracteriza pela introdução de importantes inovações técnicas no território e pela afirmação de um novo meio geográfico na região: o meio técnico. No âmbito da produção colonial vamos ter a introdução do uso do arado, enquanto na esfera da comunicação e circulação tem-se a melhoria das estradas e a conseqüente difusão do uso da carroça colonial. $\mathrm{O}$ emprego dessas inovações técnicas, resultado das ações normativas do governo provincial e dos interesses econômicos dos comerciantes e da aristocracia gaúcha, possibilitou um aumento da produção e da produtividade nas propriedades agrícolas coloniais, bem como melhores condições de deslocamento e de transporte dos produtos e das mercadorias das colônias para o mercado regional. Possibilidades essas que se ampliaram quando outras inovações técnicas engendradas pelos governos provincial e imperial, como a navegação a vapor e a ferrovia, alcançaram a região.

Contudo, é preciso ter presente que essa transição para o meio técnico não se fez com a mesma velocidade, com a mesma intensidade e com a mesma abrangência espacial seja entre os lugares da região, seja entre os setores da economia regional, bem como entre as esferas da produção e da circulação. A lógica e a dinâmica de instalação e de funcionamento desse novo meio, na verdade desses meios técnicos com seus respectivos objetos geográficos, vinculavam-se ao modo como, nesse período, se desenvolviam as ações e as relações entre os agentes que vivenciavam o território regional.

$\mathrm{O}$ artigo está organizado em três partes. Inicialmente, analisamos o processo de produção simples de mercadorias nos núcleos coloniais instalados na região do Vale do Rio Pardo abordando suas principais características. Em seguida, refletimos sobre a importância da fumicultura na produção mercantil dos núcleos coloniais, bem como sobre o processo de subordinação econômica dos fumicultores aos comerciantes coloniais, e os novos modos de uso e de organização do território advindos com a introdução de inovações técnicas na produção e circulação dos 
SILVEIRA, R.L.L. da. Pequena produção mercantil, meio técnico e rede ... produtos coloniais. Por fim, analisamos a constituição e o funcionamento da rede comercial colonial que ligava os núcleos coloniais à Porto Alegre, bem como o seu papel na acumulação de capital mercantil e seus reflexos na dinâmica de usos do território e de organização espacial na região, nesse período.

\section{O sentido da produção simples de mercadorias nas colônias da região}

Após a fase inicial de instalação dos núcleos coloniais na região e da promoção de uma economia de subsistência das unidades familiares de produção, começa a se configurar a partir de 1860 um novo momento no processo de organização do território. Trata-se da transição para um novo estágio da economia colonial, aquele da produção simples de mercadorias, tanto agrícolas como artesanais, para o mercado, quando essa parcela do território passou a ser usada e organizada, cada vez mais, de acordo com uma lógica e seguindo uma dinâmica própria à economia mercantil.

Diante da crise do então regime de acumulação capitalista brasileiro no qual o trabalho escravo predominava nas lavouras monocultoras de exportação, novas relações de produção começaram a ser estimuladas pelo Estado e pela aristocracia brasileira como modo de viabilizar melhores condições ao desenvolvimento do capitalismo no país. Entre essas novas relações de produção se insere a colonização de imigrantes europeus em pequenas propriedades familiares que acabaram permitindo o desenvolvimento de um novo e específico modo de acumulação privada do capital, na medida em que esse passava também a ocorrer através da apropriação, na esfera da circulação, do excedente produzido não capitalistamente. Ou seja, as unidades camponesas de produção instaladas nas zonas de colonização européia no Sul do Brasil, enquanto expressão de relações nãocapitalistas de produção, tornaram-se estratégicas à acumulação e à 
SILVEIRA, R.L.L. da. Pequena produção mercantil, meio técnico e rede ...

própria reprodução do capital naquele momento da economia brasileira.

Nessa mesma direção, Martins (1986, p.157) assinala que “o capitalismo engendra relações de produção não-capitalistas como recurso para garantir a sua própria expansão, como forma de garantir a produção não-capitalista do capital, naqueles lugares e naqueles setores da economia que se vinculam ao modo capitalista de produção através das relações comerciais".

Assim, a colonização estimulada no Sul do Brasil pela política de imigração significava a incorporação das áreas coloniais - onde a produção se desenvolvia sob relações de produções não capitalistas - ao mercado capitalista. Essa incorporação se fez de modo subordinado, na medida em que implicava “... por um lado, o estabelecimento de uma relação de troca de mercadorias desfavoráveis às mesmas [às colônias], e, por outro lado, a introdução de produtos industrializados que concorriam com os artesanatos e manufaturas locais, tendo por conseqüência a transformação ou destruição destes”. (MONTALI, 1979, p.19).

A inserção da economia colonial ao mercado capitalista, a partir da metade do século XIX, se implementava na medida em que ocorria a expansão da produção e o comércio do café, bem como a instalação das primeiras manufaturas e indústrias em São Paulo, Minas Gerais e no Rio de Janeiro, com base na difusão do trabalho assalariado. A ativação do mercado consumidor, especialmente em São Paulo, demandava da zona colonial produtos alimentares e matérias-primas, enquanto, por sua vez, as colônias constituíam-se em importante mercado para os produtos manufaturados ou industrializados dos principais centros industriais do país, ou mesmo por eles intermediados, quando importados do exterior. (CASTRO, 1971; SINGER, 1977 e OLIVEIRA, 1989).

Se por um lado, a dinâmica do mercado interno nacional aparece como uma variável importante no entendimento de como se dá a passagem para a economia mercantil nas colônias da região, por outro lado ela é insuficiente para que entendamos plenamente 
SILVEIRA, R.L.L. da. Pequena produção mercantil, meio técnico e rede ... como e com que características esse processo se desenvolveu na região.

Nesse sentido, também é preciso que analisemos as variáveis que concorreram internamente, na dinâmica desse uso do território regional. Uma primeira variável foi o papel que as normas instituídas pelo governo provincial tiveram sobre o aumento da produção colonial e da busca de sua comercialização. A Lei Provincial 304, de 1854, ao impor a exigência de quitação do pagamento do lote colonial aos que se instalaram nas linhas coloniais a partir de 1854, colocava aos colonos a necessidade de começar a pagar as dívidas com o governo provincial. Os colonos instalados nas colônias particulares também tinham de saldar suas dívidas com as empresas loteadoras (SEYFERTH, 1974; e VOGT, 1997). Dessa maneira, o fim das doações de terra representou um passo importante na implantação da economia mercantil, na medida em que, a partir de então, o acesso à terra passava a ser mediado apenas pela compra, o que também aconteceu com as ferramentas e os equipamentos de trabalho agrícola. "Nessa condição de endividamento do colono mesmo antes de começar a produzir, criou-se a necessidade de gerar excedentes, monetários ou não, para amortizar as dívidas. Os excedentes quitavam as dívidas e abasteciam o mercado interno do Rio Grande do Sul e do Brasil" (DALMAZZO, 2004, p.24).

Uma segunda variável se refere à necessidade que os colonos tinham em adquirir novas terras, dado o limitado tamanho de suas propriedades originais, para garantirem a reprodução familiar. Essa necessidade era justificada seja pelo progressivo esgotamento da terra e pela perda de produtividade decorrente do sistema agrícola adotado, seja pela aproximação da maioridade e emancipação dos seus filhos, e pela preocupação em assegurar as condições de reprodução de eventuais novas famílias..

Assim, havia a necessidade de além de garantir a subsistência familiar também produzir um excedente que, através da comercialização, pudesse dotar a família de recursos adicionais 
SILVEIRA, R.L.L. da. Pequena produção mercantil, meio técnico e rede ...

que lhes permitisse honrar seus compromissos e assegurar as condições que viabilizassem a reprodução das famílias.

Uma terceira e última variável a ser também considerada foi o gradativo crescimento da demanda nos mercados locais para os produtos coloniais em função do progressivo aumento da população residente na região. A partir de 1859 vamos ter um significativo crescimento da população regional, especialmente nas áreas coloniais, seja em decorrência das novas levas de imigrantes que continuavam a chegar, seja como resultado do crescimento demográfico da população preexistente (SILVEIRA, 2007).

De acordo com dados da FEE (1996) durante o período de 1859 a 1920 o núcleo colonial de imigrantes alemães de Santa Cruz do Sul apresentou um índice de crescimento populacional da ordem de $1.277 \%$, passando no respectivo intervalo de tempo, de 2.723 habitantes para 37.500 habitantes. Crescimento esse que traduz a importância econômica desse que foi o primeiro e o mais dinâmico núcleo colonial da região, e que nessa condição viu o seu núcleo urbano concorrer com o de Rio Pardo no papel de principal mercado para a produção regional. Em um segundo plano, o núcleo colonial alemão de Venâncio Aires também começava a desempenhar a condição de importante mercado local na área colonial apresentando em 1920 cerca de 17.000 habitantes. .

Nesse período, os vínculos da economia colonial regional com o mercado revelam a diversidade e as particularidades presentes nas relações comerciais que se estabelecem na medida em que se realizam, simultaneamente e de modo desigual, em distintas escalas - do local à nacional - e alcançando, inclusive, alguns lugares em nível internacional.

\section{Pequena produção mercantil, meio técnico e cultura do fumo}

Esse momento foi significativo, pois representou a passagem para um novo estágio no processo de organização espacial dessas áreas coloniais, na medida em que o território passava então a ser 
SILVEIRA, R.L.L. da. Pequena produção mercantil, meio técnico e rede ...

usado em um outro contexto, aquele do começo de afirmação do meio técnico (SILVEIRA, 2007).

No âmbito da produção, as inovações técnicas fizeram-se sentir em menor intensidade e, quando ocorreram, limitaram-se a algumas propriedades coloniais da região. A introdução do arado, por exemplo, embora ainda se vinculasse ao predomínio de uma matriz energética natural, materializada na força animal, acabou possibilitando uma mudança do sistema técnico até então utilizado. De acordo com Seyferth (1974), após um período aproximado de 12 a 15 anos desde a ocupação do lote colonial, o desaparecimento dos troncos e das raízes remanescentes da derrubada da mata, e uma melhor condição de aquisição de animais de tração tornavam possível o uso do arado no preparo da terra para o cultivo nas propriedades coloniais. Esse, para Waibel (1979), correspondia ao segundo estágio dos sistemas agrícolas utilizados nas áreas coloniais - "o sistema de rotação de terras melhorada".

Através do emprego do arado foi possível ampliar a área de cultivo, melhorar o preparo da terra e aumentar a produtividade das lavouras, ampliando assim a produção das propriedades coloniais. Isso, contudo, não significou o abandono do sistema de rotação de terras, nem tampouco, pelo menos na maior parte das propriedades, representou a adoção de adubos.

Roche (1969, p.287) denomina esse sistema agrícola de "agricultura temporária e periódica da queimada". E assinala que, embora haja a presença do uso de ferramentas como a enxada, o arado de relha metálica e a grade, o seu emprego associado à

\footnotetext{
${ }^{1}$ Esse estágio é caracterizado por Waibel $(1979,246-255)$ pelo momento em que após a devastação da maior parte das matas, com o aumento da densidade populacional, e com a construção de estradas para carroças, tem-se um avanço no desenvolvimento técnico e econômico das propriedades coloniais. A principal inovação aqui é a introdução do arado puxado por cavalos ou bois, de modo a aumentar a capacidade de ampliar as áreas cultivadas, e de melhorar o preparo da terra, muito embora nessa fase ainda permaneça o sistema de rotação de terras.
} 
SILVEIRA, R.L.L. da. Pequena produção mercantil, meio técnico e rede ...

queimada, nesses longos anos, muito mais do que um avanço técnico na produção agrícola acabou alterando a qualidade e a fertilidade natural do solo, além de facilitar os processos de erosão pelas águas correntes e de destruição da camada de húmus do solo em grande escala. Assim, passados alguns anos, a produtividade da terra diminuía, levando à substituição de algumas culturas, como a cana-de-açúcar, à introdução de outras, como a mandioca, e à valorização daquelas culturas de importância comercial, como a do feijão e a do fumo.

É importante também destacar que nesse período nem todos os colonos, especialmente os recém chegados, possuíam condições para adquirirem alguns dos objetos técnicos necessários à preparação da terra, como o arado, ou mesmo à transformação artesanal dos produtos necessários à alimentação.

A figura 2 permite observar organização espacial das propriedades coloniais resultante do emprego desse novo sistema de produção agrícola.

Observando-a identificamos como principais características espaciais: a divisão longitudinal dos lotes, o alinhamento das edificações ao longo das estradas (picadas), o quase total desaparecimento da formação florestal originária, a importância do reflorestamento e a extensão das capoeiras.

Nesse modo de cultivo o esgotamento da terra impunha que parte da mesma fosse deixada em repouso durante alguns anos, sendo o processo de produção mantido nas outras áreas da propriedade. Ao mesmo tempo, a pequena dimensão dos lotes coloniais e a geomorfologia predominante nessa área da região terrenos dobrados - impedia um pousio adequado das terras em capoeira, o que acabava levando a um crescente desmatamento nas propriedades coloniais, limitando assim as possibilidades de ampliar a produção de modo sustentável.

Essa situação limite, aliada aos efeitos das normas provinciais e à necessidade de garantir a reprodução familiar, levou as famílias de imigrantes alemães e italianos a buscarem um maior desempenho produtivo através do desenvolvimento de culturas que 
SILVEIRA, R.L.L. da. Pequena produção mercantil, meio técnico e rede ...

obtivessem bons preços nas vendas coloniais das linhas ou das povoações e que representassem, assim, uma boa alternativa de capitalização para as famílias de camponeses.

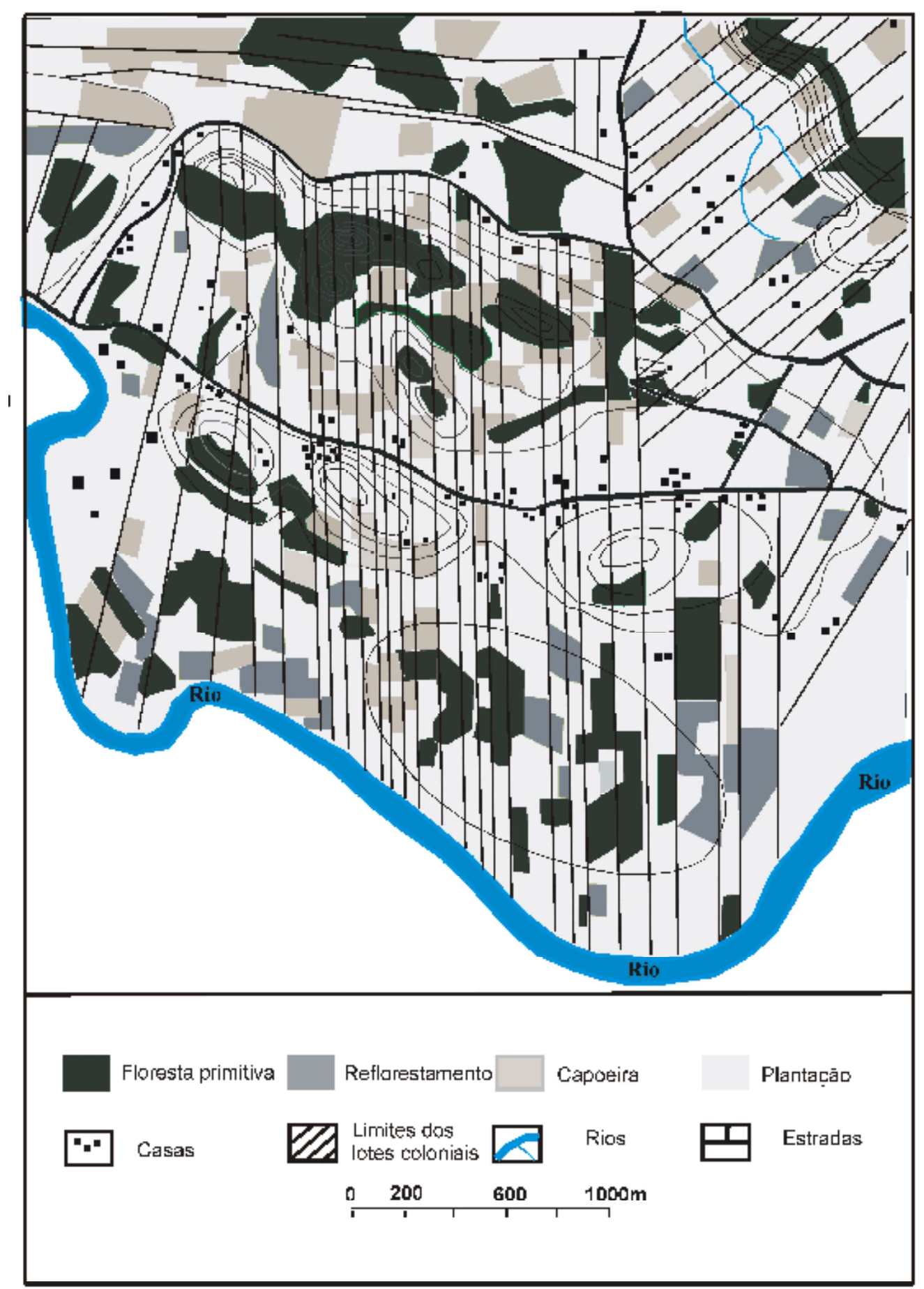

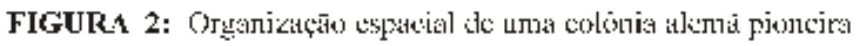

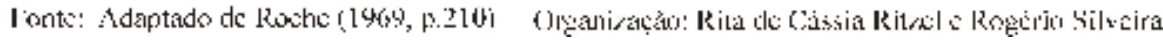

Geosul, v.25, n.50, 2010 
SILVEIRA, R.L.L. da. Pequena produção mercantil, meio técnico e rede ...

A partir de 1861, a tônica no conjunto das colônias da região foi a de que os vínculos com o mercado começavam a mudar de conteúdo na medida em que se passava de uma situação de venda de eventuais excedentes para outra na qual prevalecia a importância da produção para a venda (MONTALI, 1979).

Assim, ampliaram-se significativamente as exportações de fumo e de banha para o mercado nacional, e no caso do fumo também para o mercado internacional, enquanto a batata, a canade-açúcar, o milho e o feijão entre outros produtos se destinavam basicamente à subsistência dos produtores e ao consumo local.

Dentre as culturas desenvolvidas na região, o fumo, desde as primeiras colheitas, já se destacava, especialmente pelo fato de ser uma cultura que exigia pouco capital, que demandava um baixíssimo nível tecnológico, que podia ser cultivada em pequenas áreas de terra através do emprego da mão-de-obra familiar, e acima de tudo que aferia um bom preço no mercado, tanto para os colonos como para os comerciantes.

Nesse contexto, a produção e a exportação de fumo ampliavam-se progressivamente na região e, a partir de 1881, a economia das suas áreas coloniais acaba se especializando na cultura do fumo em folha.

Roche mostra a expansão espacial da cultura do fumo na região e as decorrentes mudanças na paisagem das propriedades coloniais.

A cultura do fumo desenvolveu-se em Santa Cruz, de onde, pouco a pouco, se estendeu para a periferia, para colônias mais recentes, como Candelária, fundada em 1863, Sobradinho, instalada em 1901, e numa parte do município de Cachoeira (distrito de Agudo). Foi ela que transformou as linhas de edificações das chácaras isoladas e das povoações: ao lado de cada casa eleva-se o barracão de fumo, secadouro de largas aberturas, cuja ventilação é regulada por lâminas de madeira que se podem orientar. Ocupa as melhores terras e a maior parte da área cultivada (ROCHE, 1969, p.184-185). 
SILVEIRA, R.L.L. da. Pequena produção mercantil, meio técnico e rede ...

A produção de fumo nesse período era realizada através do emprego intenso da mão-de-obra familiar, envolvendo inclusive o trabalho dos mais idosos e das crianças. Já o processo produtivo tinha sua dinâmica, sobretudo condicionada pelo tempo natural do ciclo de reprodução da planta, e este dependia em última instância das condições naturais existentes.

O fumo progressivamente foi se constituindo no principal produto da zona colonial do Vale do Rio Pardo e, através da sua valorização econômica e da consolidação de sua comercialização, possibilitou que a economia regional acabasse se especializando em sua produção.

\section{Circulação, rede comercial e acumulação de capital mercantil}

Enquanto a produção colonial avançava definindo especialmente o fumo e a banha como os produtos mais valorizados no mercado, a sua distribuição até os principais mercados - Rio Pardo na região, e Porto Alegre no estado - se fazia com enorme dificuldade, diante da precariedade dos meios de transporte e das vias de comunicação então existentes. Assim, para que o capital investido na produção colonial se realizasse de modo mais efetivo e com maior regularidade, se fazia urgente e necessário melhorar as condições de acesso dos produtos regionais ao mercado estadual e, sobretudo, aos mercados nacional e internacional.

O governo provincial entendia como estratégico ao projeto de colonização, especialmente nas colônias oficiais como Santa Cruz, que as mesmas conseguissem prosperar e dessa maneira recompusessem as finanças públicas e o capital ali investido. Já os comerciantes instalados nas povoações coloniais e em Porto Alegre tinham interesse em intermediar a comercialização desses produtos, bem como ampliar o seu mercado consumidor até as colônias para produtos e mercadorias, por eles trazidos, do centro do país e do exterior. Os outros segmentos da elite sulriograndense, especialmente os estancieiros e os donos de charqueadas, igualmente começavam a se interessar em adquirir 
SILVEIRA, R.L.L. da. Pequena produção mercantil, meio técnico e rede ...

aqueles produtos não produzidos em suas propriedades, ou mesmo aqueles cujo custo de importação era elevado, como o fumo. Foi a combinação desses distintos interesses que criou as condições para a introdução de importantes inovações técnicas no âmbito da circulação, tanto na escala da região, como na da província.

$\mathrm{Na}$ medida em que as picadas foram se tornando estradas carreteiras, a carroça passou a adquirir maior importância como objeto técnico mobilizado para o transporte, dada a maior capacidade de carga que ela apresentava em relação ao transporte feito pelas mulas. Já no final do século XIX a circulação, a grande distância, dos produtos, de mercadorias e de pessoas, passou a ser feita quase que integralmente através da navegação a vapor e da ferrovia (ROCHE, 1969).

A articulação dessas inovações técnicas locais - a melhoria das estradas e o uso da carreta - com os modernos meios de transporte que alcançavam a região - como o barco a vapor e o trem - tiveram grande influência na dinâmica econômica das áreas coloniais, bem como no processo de organização espacial do território regional.

A mecanização do território e a expansão do uso desses novos objetos técnicos significaram, para as áreas coloniais, uma imediata ampliação na capacidade de carga, na velocidade do transporte, na segurança do escoamento dos produtos, o que estimulou o incremento da produção colonial.

Desde o surgimento, em 1849, do transporte hidroviário a vapor, este logo começou a representar o principal meio de transporte entre as áreas coloniais e Porto Alegre. A ligação da região do Vale do Rio Pardo à linha férrea Porto Alegre - Uruguaiana, primeiro alcançando Rio Pardo, em 1883, e depois ligando Santa Cruz, em 1905, através de um ramal ferroviário, permitiu igualmente um melhor desempenho econômico por parte das áreas coloniais, especialmente quanto à exportação de seus produtos.

A figura 3 mostra as principais linhas de navegação a vapor bem como as linhas férreas que serviam a região nesse período, articulando o território regional ao mercado. Essa nova dinâmica econômica das colônias começou a estruturar-se por volta de 1860, a partir do estabelecimento de uma verdadeira rede comercial que 
SILVEIRA, R.L.L. da. Pequena produção mercantil, meio técnico e rede ... ligava, numa ponta, a produção agrícola e artesanal das propriedades coloniais e, noutra, o mercado e o porto da cidade de Porto Alegre.

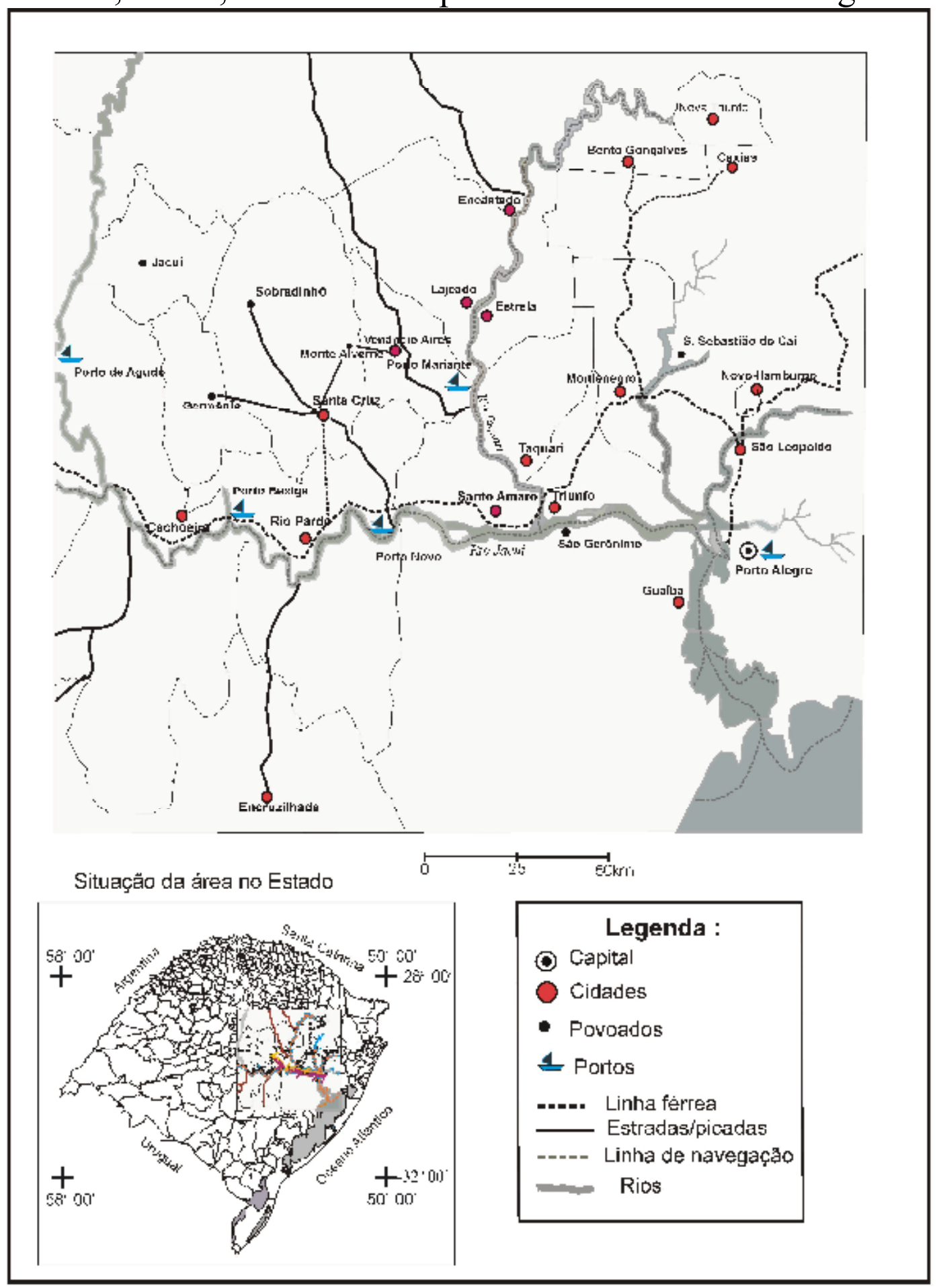

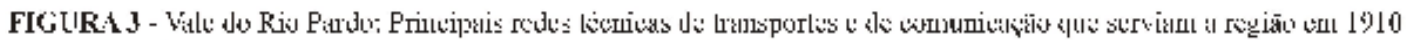

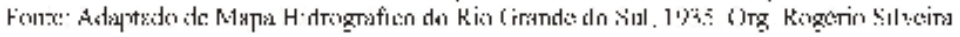


SILVEIRA, R.L.L. da. Pequena produção mercantil, meio técnico e rede ...

Para Singer (1977), a prosperidade das colônias nesse período estava intimamente vinculada à efetiva possibilidade de transporte e distribuição dos produtos e das mercadorias coloniais ao mercado consumidor de Porto Alegre, e também através dela aos mercados nacional e internacional.

Assim, devemos considerar que, tanto a lógica de instalação desses novos objetos e sistemas técnicos no território, como as possibilidades e a abrangência dos seus usos, e ainda os seus reflexos sobre o desempenho da produção colonial, se vinculam, sobretudo, à lógica e à dinâmica de funcionamento dessa rede comercial onde circulavam produtos, mercadorias e capital no território.

A configuração da rede comercial se estendia por ampla área rural da zona colonial, articulando os colonos aos comerciantes rurais em suas vendas nas picadas, estes aos comerciantes em seus armazéns e suas casas comerciais nas povoações, e estes aos atacadistas, exportadores e importadores em suas grandes casas comerciais localizadas em Porto Alegre. Além desses agentes, havia ainda o caixeiro-viajante que durante alguns anos tornou-se o intermediário imprescindível entre Porto Alegre e a zona colonial, entre o atacadista e o vendeiro varejista, trazendo mercadorias não produzidas na região, inovando e criando novas necessidades (ROCHE, 1969; MONTALI, 1979).

A razão de ser dessa rede comercial estava na impossibilidade de os próprios colonos poderem levar os seus produtos aos mercados locais e regionais, e mesmo a Porto Alegre. A distância, a precariedade dos caminhos, a inexistência de animais de carga, o dispêndio de tempo na produção, e o elevado custo que essas viagens representavam, impediam os colonos de escoarem diretamente sua produção.

Portanto, a posse de um meio de transporte que viabilizasse a circulação dos produtos e das mercadorias no território, entre os locais de produção e os de consumo, representava a condição fundamental para a realização do valor dos produtos e mercadorias a serem comercializadas. Ou seja, o poder de fazer os produtos 
SILVEIRA, R.L.L. da. Pequena produção mercantil, meio técnico e rede ... circularem no território permitia, a quem o detivesse, a possibilidade de apropriação do capital mercantil. Nas colônias localizadas na região, essa condição esteve nas mãos dos comerciantes locais ou vendeiros e, também, nas dos comerciantes das povoações das colônias. Ambos, cada um operando em níveis específicos dessa rede comercial - os primeiros no varejo, os segundos no meio atacado -, concentravam em suas mãos tanto o monopólio da atividade comercial como o dos meios de transportes. Majoritariamente, foram os comerciantes que organizaram e exploraram o serviço de transporte dos produtos coloniais em lombo de mula, depois em carroça, entre as linhas, entre as linhas e as povoações, entre estas e os portos fluviais, e mais tarde entre as linhas e a estação férrea (ROCHE, 1969).

O processo de acumulação de capital mercantil que então se desenvolvia na região revela um conjunto de ações e de relações entre os agentes que traduzem a lógica e a dinâmica pelas quais o território regional era por eles usado.

A venda colonial representava o primeiro nível da rede comercial e também se constituía na menor unidade de acumulação de capital (LAGEMANN, 1996). Sua localização na zona rural seguia o ritmo e a direção do arroteamento das terras no interior da colônia. O processo de acumulação de capital mercantil pelos comerciantes rurais foi viabilizado através da combinação de várias ações. Uma primeira ocorria através do "custo do frete". Uma segunda decorria em razão do isolamento imposto às colônias pela precariedade dos meios de comunicação e de transporte, bem como pela passividade e confiança de sua clientela, o que permitia ao comerciante promover o monopólio e a manipulação de informações e preços dos produtos, tanto os coloniais, como os importados. Desse modo, o comerciante engendrava a dependência dos colonos em relação à sua casa comercial. Por fim, uma terceira ação que possibilitava ao comerciante acumular capital era quando este desempenhava também a função de banqueiro através da guarda e/ou do empréstimo de dinheiro a juros aos colonos (ROCHE, 1969, MONTALI, 1979 e LAGEMANN, 1996). 
SILVEIRA, R.L.L. da. Pequena produção mercantil, meio técnico e rede ...

Essas ações, combinadas, criavam então as condições para a acumulação de capital mercantil pelos comerciantes, na medida em que esses se apropriavam da maior parte do sobretrabalho realizado pela mão-de-obra familiar dos colonos.

Um segundo nível dessa rede comercial foi aquele ocupado pelos comerciantes que com seus armazéns, suas casas comerciais e seus depósitos de meio atacado localizavam-se em pontos intermediários, entre as áreas rurais e a capital do Estado. Localizados nas margens dos rios, nos entroncamentos ferroviários e, notadamente, nas principais povoações coloniais, esses estabelecimentos promoviam a intermediação e redistribuição tanto dos produtos da colônia para os principais mercados consumidores, como das mercadorias importadas desde Porto Alegre para as vendas coloniais. O controle das informações sobre os preços e as mercadorias importadas, bem como o monopólio, principalmente do transporte fluvial dos produtos coloniais para a capital, permitia que esses comerciantes igualmente se apropriassem de parcela do sobretrabalho dos produtores familiares rurais.

$\mathrm{Na}$ medida em que houve a progressiva melhoria das vias de transporte até a capital, através da navegação fluvial a vapor, da ferrovia e das estradas de rodagem, as grandes casas comerciais, de importação e de exportação, localizadas em Porto Alegre, consolidaram-se como principais locais de comercialização da produção colonial e também como pontos centrais de abastecimento das vendas e casas comerciais localizadas nas povoações e áreas rurais das colônias. Muitas vezes, os laços econômicos com as casas comerciais da capital eram reforçados com a abertura de filiais ou de depósitos nas principais paradas das vias de transporte (portos e estações), e também através do envio às vendas coloniais, de seus caixeiros-viajantes. Daí sua condição de terceiro e principal nível na configuração da rede comercial.

O grande comércio estabelecido em Porto Alegre assumia assim a condição de comando dessa rede comercial, na medida em que controlavam oligopsonicamente a importação de mercadorias do centro do Brasil e do exterior e sua posterior distribuição para o 
SILVEIRA, R.L.L. da. Pequena produção mercantil, meio técnico e rede ...

interior do Rio Grande do Sul, bem como a exportação dos produtos coloniais. Eram os grandes comerciantes quem impunham os preços, as tarifas de transporte, as taxas de importação e exportação. Seu poder econômico também era expresso através do protagonismo na condução de toda a logística e organização necessária ao desenvolvimento da atividade comercial, como a exploração de empresas de navegação fluvial e lacustre, de empresas de transporte rodoviário, a atuação em casas bancárias, agências de corretagem, de seguros e de representação comercial. Além disso, sua importância se manifestava pelos laços comerciais que esses grandes comerciantes teuto-brasileiros mantinham com as casas comerciais alemãs, na Alemanha, bem como era reforçada na medida em que, a partir de 1875 , foram abertas linhas marítimas ligando o Rio Grande do Sul à Alemanha e ao restante da Europa (ROCHE, 1969).

Assim, a dinâmica de funcionamento da rede comercial demandava um conjunto de relações entre os distintos níveis de sua estrutura que resultavam da divisão de funções comerciais e simultaneamente da articulação, da negociação, mas também da disputa entre os seus agentes constituintes pelo fundamento mesmo dessa rede: a apropriação do sobretrabalho das famílias de agricultores coloniais. Por sua vez, se essas foram as características e os fundamentos básicos que nortearam o desenvolvimento dessa rede comercial, também é preciso reconhecer que o processo de comercialização de cada produto colonial apresentou particularidades e diferenças quanto às áreas e aos lugares que economicamente integrava, bem como quanto às possibilidades de valorização mercantil de cada produto.

A contribuição de Vogt sobre o processo de comercialização do fumo, embora longa, é fundamental para que tenhamos presente que o processo de acumulação de capital mercantil não foi homogêneo nos diferentes lugares da zona colonial da região do Vale do Rio Pardo. 
SILVEIRA, R.L.L. da. Pequena produção mercantil, meio técnico e rede ...

Em primeiro lugar é preciso deixar patente que não foram todos os comerciantes que tiveram condições econômicas para poder lidar com o tabaco. Em segundo, que juntamente com o fumo, os vendistas também negociavam ferragens, fazendas, calçados, louças, artigos de armarinho, secos e molhados, o que lhes garantia a otimização do funcionamento das contas correntes, além de possibilitar maior acúmulo de capitais. Em terceiro, é indispensável frisar que houve a tendência das casas comerciais de beneficiamento de fumo surgirem na sede do município ou nas vilas dos distritos, sendo que estas últimas, na medida em que os empreendimentos tornavam-se mais vultosos, também se transferiam para o núcleo urbano, em virtude das melhores condições infra-estruturais aí existentes. Em quarto lugar, é preciso enfatizar que a maioria dos comerciantes existentes nas picadas que trabalhavam com fumo, atuava através dos seus pontos de compra do produto, como representantes de "comerciantes mais fortes", os enfardadores, localizados nas sedes distritais, núcleo municipal ou mesmo na capital do Estado. Assim, havia situações em que o produtor rural despachava o seu cultivo através da casa comercial local - que repassava adiante a mercadoria para outro comerciante - como havia casos em que o colono transacionava diretamente o fruto do trabalho da sua família com a firma existente na sede administrativa de Santa Cruz (VOGT, 1997, p.95-96).

\section{Considerações finais}

Nesse sentido, podemos constatar a importância que a produção e a comercialização do fumo adquiriram no conjunto da economia regional, através de sua destacada participação na rede comercial. Essa participação possibilitou a acumulação de capital nas áreas coloniais, especialmente em seus principais núcleos urbanos; além disso, acabou orientando os novos investimentos necessários à reprodução do capital, refletindo, em nosso ver, o 
SILVEIRA, R.L.L. da. Pequena produção mercantil, meio técnico e rede ...

grau de especialização que as áreas coloniais da região passaram a apresentar.

Por outro lado, o fato de a produção colonial, especialmente a agrícola, somente ter efetivado seu valor de troca mediante a intermediação monopólica dos comerciantes, levou simultaneamente ao isolamento e à subordinação do pequeno produtor familiar em relação ao mercado. $\mathrm{O}$ produtor, dependente desse intercâmbio desfavorável, embora mantivesse a propriedade da terra, via-se, dessa forma, progressivamente submetido à lógica e à dinâmica de reprodução do capital comercial. Além disso, na medida em que consideramos o uso predominante de um sistema técnico rudimentar na produção colonial e a progressiva fragmentação do minifúndio familiar - resultado do parcelamento da terra entre os descendentes familiares -, acabamos por revelar a situação de crescente perda de produtividade das pequenas propriedades e de pauperização dos camponeses de origem imigrante que viviam na região.

Observa-se também que a lógica e a dinâmica de funcionamento da rede comercial, articulando seus distintos níveis de comercialização, acabaram engendrando as condições para a promoção de uma dada solidariedade espacial, na medida em que articulava lugares de distintas escalas geográficas - a pequena propriedade e a venda na linha colonial; os núcleos de povoação; os centros comerciais regionais, como Rio Pardo, a capital Porto Alegre; e os centros comerciais nacionais, como o Rio de Janeiro e São Paulo, e internacionais, como Hamburgo, na Alemanha. A materialização dessa solidariedade espacial no território se efetivou através de relações sociais e econômicas fundamentadas na lógica mercantil, na busca da apropriação do sobretrabalho das famílias de camponeses coloniais e na realização da acumulação de capital mercantil. Para tanto, foi de vital importância o modo como os diferentes agentes acessaram e usufruíram dos serviços decorrentes das inovações técnicas instaladas na região, especialmente no âmbito da circulação e da comunicação. Os reflexos do funcionamento da rede comercial, bem como os efeitos dos usos 
SILVEIRA, R.L.L. da. Pequena produção mercantil, meio técnico e rede ...

predominantes desses objetos e sistemas técnicos incidiram ativamente na organização espacial e no modo de uso do território onde, além do aumento da população, do aumento da área cultivada e da produção, do surgimento de povoações, houve um forte crescimento da economia das colônias, através da sua especialização pela fumicultura.

Tal especialização da economia colonial da região acabou também incidindo ativamente no modo como, a partir de então, as áreas rurais e os núcleos urbanos coloniais se integraram à divisão territorial do trabalho regional e nacional, e simultaneamente, no modo desigual e diferenciado como cada cidade participou do processo posterior de formação e de evolução da rede urbana do Vale do Rio Pardo.

\section{Referências bibliográficas}

CASTRO, A.B. de. Sete ensaios sobre a economia brasileira. Rio de Janeiro/São Paulo: Ed. Forense, Vol. II, 1971.

DALMAZZO, R.A . As relações de comércio do Rio Grande do Sul - do século XIX a 1930. Porto Alegre: FEE, Documentos FEE 60, 2004.

FUNDAÇÃO DE ECONOMIA E ESTATÍSTICA. De província de São Pedro a Estado do Rio Grande do Sul. Censos do RS: 1803-1950. Porto Alegre: FEE, 1986.

LAGEMANN, E. Imigração e industrialização. In: DACANAL, J.H. (Org.). RS: Imigração \& colonização. Porto Alegre: Ed. Mercado Aberto, 1996, p.114-134.

MARTINS, J. de S. O cativeiro da terra. São Paulo: Ed. Hucitec, 1986. 
SILVEIRA, R.L.L. da. Pequena produção mercantil, meio técnico e rede ...

MONTALI, L. Do núcleo colonial ao capitalismo monopolista: produção de fumo em Santa Cruz do Sul. São Paulo: USP. Dissertação de Mestrado em Sociologia, 1979.

OLIVEIRA, F. de. A economia da dependência imperfeita. Rio de Janeiro: Ed. Graal, 1989.

ROCHE, J. A colonização alemã e o Rio Grande do Sul. Porto Alegre: Ed. Globo, Vol. 1, 1969.

SEYFERTH, G. A colonização alemã no Vale do Itajaí-Mirim. Porto Alegre: Ed. Movimento/SAB, 1974.

SILVEIRA, R.L.L. da. Complexo agroindustrial do fumo e território: a formação do espaço urbano e regional no Vale do Rio Pardo. Tese de Doutorado. Florianópolis: UFSC. Programa de Pós-Graduação em Geografia. 2007.

SINGER, P.I. Desenvolvimento econômico e evolução urbana. São Paulo: Ed. Nacional, 1977,

VOGT, O. A produção de fumo em Santa Cruz do Sul: 18491993. Santa Cruz do Sul: EDUNISC, 1997.

WAIBEL, L. Capítulos de Geografia tropical e do Brasil. Rio de Janeiro: IBGE, 2 $2^{\mathrm{a}}$ edição. 1979. 
